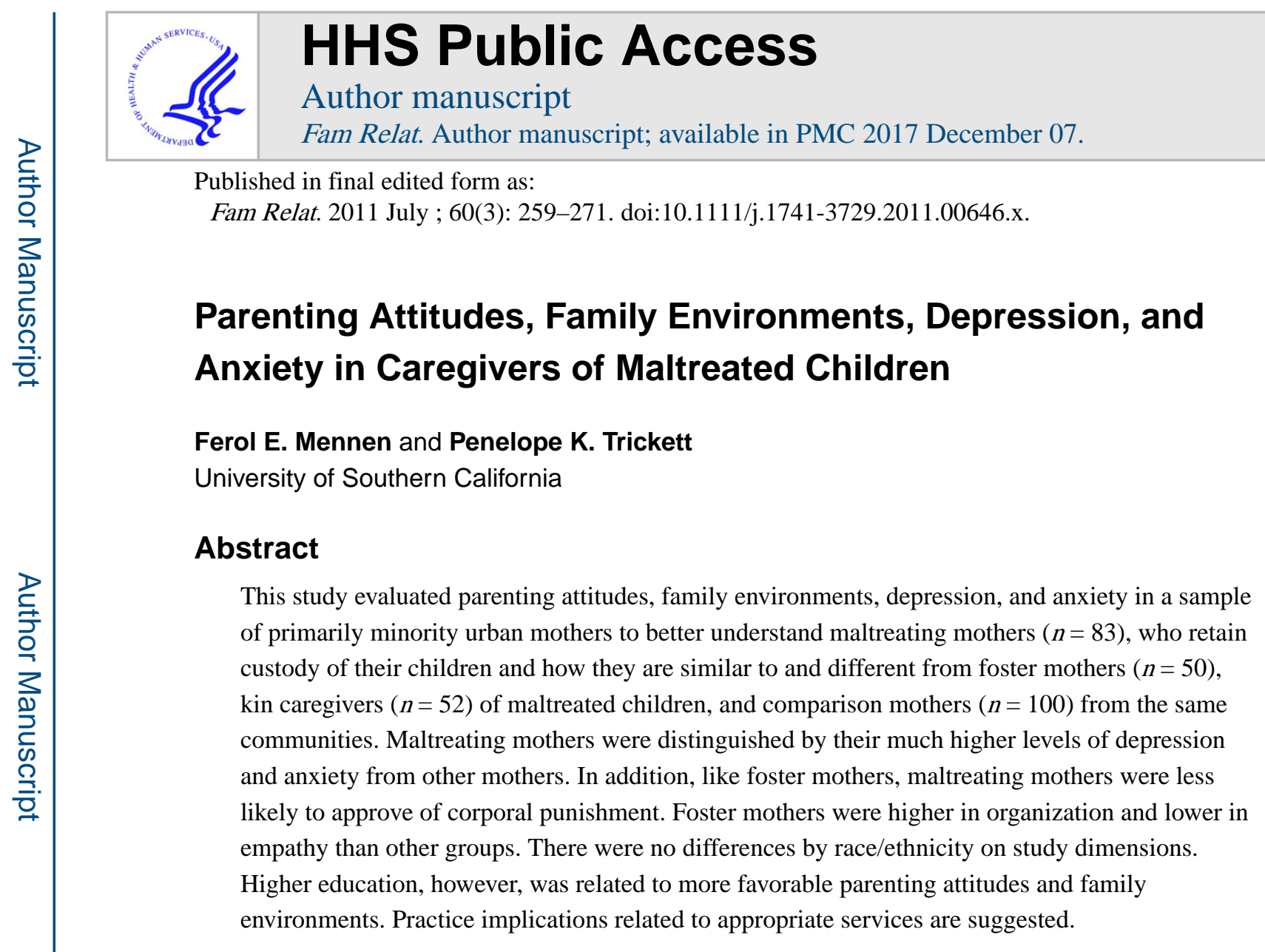

\title{
Keywords
}

child abuse and neglect; maltreating parents; parenting attitudes

Child maltreatment is one of the most serious social problems affecting children and their families. The child welfare system is charged with the responsibility of making decisions on how to handle cases reported to authorities. With the passage of the Adoption and Safe Families Act of 1997, there has been a shift from placing children in nonrelative foster care to keeping children with their maltreating parents or, if this is not possible, placing them with relatives (Allen \& Bissell, 2004). The latest statistics available in 2009 indicate that of 753,357 reported victims of maltreatment in 2007 , only $20.7 \%$ of them were removed to out of home care (U.S. Department of Health and Human Services, 2009a). Of the children in foster care in 2008, 24\% were living in relative care (U.S. Department of Health and Human Services, 2009b).

This reliance on in-home or relative care demands that we know more about these caregivers. The purpose of this study was to learn more about the levels of depression, anxiety, parenting attitudes, and characteristics of family environments in a sample of maltreating mothers after maltreatment has occurred and to determine how these characteristics are similar to or different from foster mothers and kin caregivers of maltreated children and nonmaltreating comparison mothers in the same communities. 
Understanding more about the mothers who care for maltreated children will offer insights that can aid in developing interventions that will create better outcomes for the mothers and their children.

The etiology of child maltreatment is complex and related to characteristics of the parents and children, the surrounding ecology, the situation in time, and social factors, among other things (Belsky, 1993; Bronfenbrenner, 1979; Cicchetti \& Toth, 1995). The retrospective nature of this study does not allow us to try to determine the reasons these mothers maltreated their children but it can allow us to get a better picture of their current functioning as they seek to continue to parent after maltreatment.

\section{Maltreating Mothers}

There have been many studies over the years that have looked at maltreating parents to discover the attributes that distinguish them from those who do not maltreat their children. Those studies have focused primarily on parenting attitudes and practices, psychological functioning, and family environment. The participants in these studies were either exclusively or primarily women. Trickett and Susman (1988), in a study on physically abusive mothers and a demographically similar comparison group of mothers, found that the abusive mothers were less satisfied with their children, found parenting more difficult, and, as measured by the Family Environment Scale (FES), were higher in conflict and expressed less positive emotion. Wiehe (2003) compared a sample of parents who were physically and emotionally abusive ( $74 \%$ women) with a sample of foster parents (over $84 \%$ women) from the same agency on measures of empathy and narcissism and found that the abusive mothers had less self-confidence, had poorer impulse control, were more narcissistic, and were less empathic than the foster mothers. The two groups did not differ by race, although the foster mothers had more education than the abusive mothers. A study on physically abusive parents (89\% mothers) and comparison parents (80\% mothers), matched on socioeconomic status, child age, gender, education, and family size, were evaluated on the cognitive and affective variables that predicted abuse. This study found that the likelihood of being an abusive parent increased as the number of risk factors increased (Haskett, Scott, Grant, Ward, \& Robinson, 2003). The only unique predictor was the mother's perception of her child's behavior as problematic. The addition of a combination of parental psychopathology and parenting stress also increased the prediction of abusive parenting.

In relation to beliefs about discipline, Linares, Montalto, Rosbruch, and $\mathrm{Li}$ (2006) found in their comparison of maltreating parents and foster parents (again primarily mothers) that the two groups had similar attitudes in relation to disciplinary strategies, with both endorsing positive discipline and appropriate discipline over harsh discipline. What differentiated the groups were the foster mothers' clearer expectations for children's behavior and biological mothers' higher levels of psychological distress. Finally, Whipple and Webster-Stratton (1991), in their sample of families seeking treatment for children with conduct problems, found that maternal spanking predicted abusive parenting.

Depression has been the most frequently studied parental psychological dimension. The focus on depression is understandable, because it has consistently been related to 
problematic parenting and poor child outcomes (Burke, 2003; Cummings \& Davies, 1994; Lovejoy, Graczyk, O'Hare, \& Neuman, 2000). The most common finding is the elevated levels of depression in maltreating mothers (e.g., Famularo, Fenton, Kinscherff, Ayoub, \& Barnum, 1994; Kelleher, Chaffin, Hollenberg, \& Fisher, 1994; Kinard, 1996; Mammen, Kolko, \& Pilkonis, 2002; Walsh, MacMillan, \& Jamieson, 2002; Zuravin, 1989). A few studies have expanded on this to compare maltreating mothers and nonmaltreating mothers of maltreated children to understand the differences in the two. Specifically, Kinard, in a longitudinal study, found no differences between rates of depression at Time 1. More than half of both groups met the criteria to be considered depressed. At Time 2, both groups had declined in depression with nonmaltreating mothers having greater declines, leaving the maltreating mothers with higher levels of depression. Baumann and Kolko (2002), however, found no differences in psychological functioning on the Brief Symptom Inventory (BSI) between maltreating and nonmaltreating mothers of abused children.

Although anxiety is often related to depression (Kaufman \& Charney, 2000; Krueger, 1999), it has less often been a focus of studies on maltreating parents. Although a number of studies have reported elevated rates of anxiety in samples of maltreating parents (mostly mothers; Brunnquell, Crichton, \& England, 1981; Perry, Wells, \& Doran, 1983; Whipple \& WebsterStratton, 1991), Mammen et al. (2002) found that although physically abusing parents had rates of anxiety higher than national norms, anxiety was not related to physically abusing a child.

The most clearly replicated finding in the cited studies is that maltreating mothers seem to have higher levels of psychological problems than other mothers. These studies do not allow us to conclude that these attributes lead to the maltreatment itself because they were conducted after the maltreatment had been identified.

\section{Foster Mothers}

Much of the recent research on foster parents (again samples are primarily or exclusively women) has focused on issues related to motivation to foster, retention of foster parents, and on attitudes toward fostering (e.g., Gibbs \& Wildfire, 2007; Orme et al., 2004) rather than characteristics of the mothers themselves. A comprehensive review of the research on foster parents, their attributes, and effect on children's functioning was done by Orme and Buehler (2001); as they noted, much of the previous research suffers from small samples, nonstandardized measures, failure to account for kin versus nonkin foster parents, lack of comparison groups, and almost no longitudinal research. They further noted that little is known about foster parents' mental health—as this dimension is rarely studied. They summarized studies focusing on parenting attitudes by noting that about $15 \%$ of foster parents displayed problematic parenting. The authors concluded that not nearly enough is known about the attributes and parenting attitudes of foster parents and the way those relate to children's functioning.

Other research on foster mothers most frequently either compares them to birth mothers or compares kin foster mothers with nonrelative foster mothers. In relation to the comparison of kin and nonrelative foster caregivers, the majority of studies have found that kin care- 
givers are older, less educated, poorer, and from more disadvantaged neighborhoods than the nonrelative foster caregivers (Berrick, Barth, \& Needell, 1994; Christenson \& McMurtry, 2007; Ehrle \& Geen, 2002; Gebel, 1996; Harden, Clyman, Kriebel, \& Lyone, 2004). A small number of studies have looked at the psychological functioning of foster mothers. Lipton (1997) found that foster and adoptive mothers of sexually abused children reported better functioning on the BSI than the biological (but nonoffending) mothers of sexually abused children. Cole and Eamon (2007) found very low rates of depression in their sample of foster caregivers (92.1\% women) with only 1 of 189 caregivers having a clinical level of depression.

Attitudes toward parenting and parenting behaviors have also been studied. Several researchers have found that kinship foster mothers are more likely to endorse harsh discipline methods, including physical punishment, than nonkin foster mothers (Brooks \& Barth, 1998; De Robertis \& Litrownik, 2004; Gaudin \& Sutphen, 1993; Gebel, 1996; Litrownik, Newton, Mitchell, \& Richardson, 2003). Barth et al. (2008) did not find differences between kin and nonkin foster parents in punitiveness in their analysis of National Study of Child and Adolescent Well Being data, with about one third of each group scoring in the high punitiveness group. Furthermore, Harden et al. (2004) found that the female kin caregivers reported more parent/child anger, less warmth/respect, and more strictness/overprotectiveness. When age and marital status of the caregivers were added to the regression, however, only those factors predicted the difference between kin and nonkin caregivers. Specifically, kin foster mothers were more likely to be older and single. Gebel found that kin foster mothers had lower levels of empathy than nonrelative foster mothers, but similarly, he also found in a multivariate analysis that the type of caregiver was no longer a significant predictor of attitudes when education and race of the caregivers were added to the analysis.

Differences have also been found in the way these two groups of caregivers perceive the problems of the foster children. Kin foster mothers often see the children in their care as less distressed and problematic and less affected by their maltreatment experience than nonrelative foster mothers (Berrick, 1997; Gebel, 1996; Holton, Ronning, Handegard, \& Sourander, 2005; Keller et al., 2001; Timmer, Sedlar, \& Urquiza, 2004). Whether this represents a real difference in functioning is not clear, as many of the studies that evaluate mental health problems in maltreated children utilize parental report measures to evaluate their children's functioning and need for services.

The goal of this descriptive study was to enhance our understanding of the functioning of maltreating mothers of abused children; we were not attempting to explain why these mothers maltreated their children. The causes of child maltreatment are multidimensional (Cicchetti \& Toth, 1995) and cannot be addressed in a retrospective study. We were interested in constructs that are related to parenting, could be expected to relate to the effectiveness of caretakers to deal with the problems maltreated children bring to family life, and that previous research has highlighted as important. The specific research questions were as follows: 
1. Are there differences in the levels of depression and anxiety of biological mothers, kin foster mothers, and nonkin foster mothers of maltreated children, and how do these groups compare with the levels of anxiety and depression of mothers of nonmaltreated children?

2. Are there differences in dimensions of family environments, specifically related to conflict/anger, cohesion, and organization of biological mothers, kin foster mothers, and nonkin foster mothers of maltreated children, and how do these groups compare to mothers of nonmaltreated children?

3. Are there differences in the parenting attitudes of biological mothers, kin foster mothers, and nonkin foster mothers of maltreated children, and how do these groups compare with the parenting attitudes of mothers of nonmaltreated children?

\section{Method}

The families for this study were participating in a longitudinal study on the impact of child abuse and neglect on adolescent development. The sample included both families with maltreated children and comparison families with nonmaltreated children from the same communities. Interview and recruitment procedures were approved by the Institutional Review Board of the University of Southern California and the Los Angeles County Juvenile Court. Maltreated children and their families were recruited from the local child welfare agency. The agency assembled lists of cases with a new referral that had been opened within the past 30 days and that met the following criteria: The child was between 9 and 12; either Latino, African American, or White; and resided within specified zip codes. The zip codes were chosen to represent geographic areas with sizable numbers of African American, Latino, and White children; had substantial rates of maltreatment; and were accessible to the study site. Caregivers of the children were contacted by letter from the agency advising them of the study and asking if they would like to participate. We followed up this letter with a phone call in which we explained details of the study, and caregivers could decide if they would like to participate. Of those families who received the letter, $77 \%$ agreed to participate in the study. Families were contacted within 3 months of the report of maltreatment that got them into the study.

Comparison families were recruited from school lists and a direct marketing service that provides names, addresses, and phone numbers by geographic area. The comparison families were chosen from the same zip codes as the maltreated children to ensure that they would have similar neighborhood experiences. A similar process of recruitment occurred, with initial mail contact followed up by a phone call when caregivers decided to participate. There were a large number of incorrect addresses, making participation rates difficult to estimate, but approximately $50 \%$ of those who received letters agreed to participate.

To evaluate neighborhood similarity of the two groups, comparisons were made on nine census categories relevant to characterizing the social, educational, economic, and demographic nature of neighborhoods and deemed important for child development (Duncan $\&$ Aber, 1997). Independent-sample $t$ tests were conducted for each category of each census 
characteristic. For example, for the dimension, "Percent of People of Different Ages," twogroup $t$ tests were carried out for each of 10 age categories. For this set of comparisons, a statistically significant difference was found for one age category (percentage 40 to 49 year olds), where the average of $12 \%$ for the maltreated group differed statistically from the $13 \%$ for the comparison group. In 72 comparisons of this kind, nine statistically significant differences were found. Like the difference reported above, none of these differences were large-and theoretically, not likely to produce an effect through a relationship with other variables. The range of differences between the samples in percentages for the 72 comparisons of the nine characteristics was from 1 to $4 \%$ (with a median of $2 \%$ ). This indicates that, overall, for the dimensions examined, the neighborhoods of the maltreatment group and the comparison group were very similar.

Children and caregivers came to the project office and took part in a lengthy interview conducted by doctoral students in social work and psychology with extensive training in the measures. The interview included measures on attitudes toward parenting, family environment, and psychological functioning. All instruments were available in English and Spanish. When a validated translation was not available through the author, measures were translated and back translated. They were then piloted on volunteers to ensure comparability. A bilingual interviewer interviewed the Spanish-speaking caregivers. All families were compensated for their participation in the study.

\section{Measures}

Demographic information-We gathered demographic data on a form developed for the study. Among the information gathered was the relationship of the caregiver to the study child and the caregiver's age and education. For the purpose of this study, the caregiver's education was collapsed into four categories, less than high school education, high school diploma, some college but no degree, and a college degree or more. We used education categories used in health research (see Goodman, 1999; Goodman \& Huang, 2002) but collapsed college degree and advanced degree into a single category because of the small number of advanced degrees in this sample. With permission from the child and family, we obtained the children's records from DCFS that contained the material about maltreatment allegations and investigations. These records contained information about who had perpetrated the reported maltreatment. We reviewed and abstracted these records (the detailed process can be found in the studies by Mennen, Kim, Sang, and Trickett, 2010, and Trickett, Mennen, Kim, and Sang, 2009). Many of the children had multiple reports of maltreatment and had suffered more than one kind of maltreatment. Biological mothers were coded as having perpetrated maltreatment or not having perpetrated maltreatment. Information about the kinds of services they received from child welfare was not available to the researchers.

Psychological functioning-The BSI (Derogatis \& Melisaratos, 1983) is a self-report measure designed to assess psychological symptoms and is a shorter version of the Symptom Checklist-90-R (Derogatis, 1993). Both these scales have extensive support for their reliability and validity and have been used cross culturally (see Iwamasa \& Kooreman, 1995; Ruiperez, Ibanez, Lorente, Moro, \& Ortet, 2001). Questions ask in the past 7 days 
how often the respondent has been bothered by certain symptoms. Answers are on a 5-point Likert scale from 0 (never) to 5 (almost always). We chose to focus on the depression subscale (sample $a=.87$ ) because of the previously noted implication of depression in problematic parenting and the anxiety subscale (sample $a=.92$ ) because of its frequent concurrence with depression (Kaufman \& Charney, 2000). Scores can range from 0 to 30, with higher scores reflecting more problematic functioning.

Family environment-We evaluated the family environment with subscales from the FES (Moos \& Moos, 1994). This self-report measure has been widely used in studies on family processes and has been shown to be reliable and valid among different populations and with different racial/ethnic groups (Boyd, Gullone, Needleman, \& Burt, 1997; Clay, Ellis, Griffin, Amodeo, \& Fassler, 2007; Negy \& Synder, 2006; Sanford, Bingham, \& Zucker, 1999). For the purpose of this study, we utilized the subscales of conflict/anger (sample $a=.85$ ), organized/structure (sample $a=.66$ ), and cohesion/expression (sample $a=.75$ ). These dimensions have been found to relate to scores on the Child Abuse Potential Inventory (Milner, Gold, \& Wimberley, 1986) in maltreating parents (Mollerstrom, Patchner, \& Milner, 1992). Respondents answer true (1) or false (0) to questions such as "In this family things are pretty carefully planned" from the organized/structure subscale. Scores on each subscale depend on the number of items but could range from 0 to $11-14$. We removed two items from the organized/structure subscale to improve the $a$ s, with higher scores reflecting more positive responses on the scale.

Parenting attitudes-We evaluated caregivers' attitudes about parenting with the AdultAdolescent Parenting Inventory-2 (AAPI-2; Bavolek \& Kenne, 1999). This widely used measure is a revision of the earlier version and has been used extensively to determine problematic attitudes toward parenting including those that may relate to child maltreatment (Conners, Whiteside-Mansell, Deere, Ledet, \& Edwards, 2005; Devoe \& Kantor, 2002). It has 40 items with possible responses on a 5-item Likert scale ranging from strongly agree to strongly disagree to questions (e.g., "Children learn respect through strict discipline"). There are five subscales reflecting different dimensions of parenting: inappropriate expectations of child (in our sample $a=.70$ ), parental lack of empathy to children's needs (in our sample $a$ $=.74$ ), strong belief in use of corporal punishment (in our sample $a=.78$ ), reversing parent child roles (in our sample $a=.73$ ), and oppressing children's power and independence (in our sample $a=.45$ ). The last scale was eliminated in the present analysis because of low internal consistency. Higher scores reflect more favorable parenting attitudes.

\section{Participants}

The sample included 348 caregivers of 454 children ( 303 maltreated and 151 comparison). The caregivers were $89 \%$ women. Of these 310 female caregivers, 100 were mothers of comparison children, 51 were foster mothers, 52 were female kin caregivers (26 grandmothers, 14 aunts, 4 sisters, and 6 other female relatives), and 107 were biological mothers of the maltreated children. Of the biological mothers, 83 (77.6\%) had perpetrated maltreatment and were the sample of biological mothers for the study. There were no differences for the four groups of caregivers by race or ethnicity $\left(\chi^{2}=13.6, p>.05\right)$; however, there was a difference in age $(F=22.2, p<.000)$. Comparison mothers and 
biological mothers were younger than foster mothers and kin caregivers. (See Table 1 for more demographic characteristics. $)$ The groups also differed in education $\left(\chi^{2}=35.0, p<\right.$. 000), with biological mothers and kin caregivers more likely to have less than a high school education and foster and comparison mothers more likely to have some college or a college degree. There was a difference in the Latina caregivers by language they preferred for the interview $\left(\chi^{2}=11.3, p<.01\right)$ with biological mothers and foster mothers more likely to prefer Spanish than the kin caregivers and comparison mothers.

\section{Data Analysis Strategy}

To limit the possibility of Type I errors, we used multivariate analysis of covariance (MANCOVA) on subscales of the BSI, FES, and AAPI, with dependent variables with the relationship of the caregiver entered as a fixed factor. Education, language, and race/ ethnicity were also entered as factors to control for them. We found a difference by language on organized/structure subscale of the FES $(F=10.19, p<.01)$ and the lack of empathy $F=$ $16.72, p<.01)$ and the reversing parental roles $(F=27.70, p<.01)$ of the AAPI. Therefore, to control for language, we entered it as a factor. We also controlled for race/ethnicity, as it has been found to relate to differences in parenting attitudes. Finally, the caregiver's age was entered as a covariate. We followed MANCOVA results with univariate analysis of covariance (ANCOVA) with LSD post hoc comparisons to understand the relationships of the variables.

\section{Results}

The correlation between the outcome variables can be found in Table 2. Beyond the significant correlations of the different subscales of the measures, which are to be expected, there were a number of notable correlations. The depression and anxiety subscales of the BSI were moderately correlated with conflict/anger on the FES. There were moderate negative correlations between the AAPI subscales of inappropriate expectations, lack of empathy, and reversing roles with the organized/structure subscale of the FES.

The MANCOVA indicated that caregiver relationship was significantly associated with subscales on the BSI, FES, and AAPI $(F=103.8, p<.001$; see Table 3 for MANCOVA results). Power for the multivariate test was .999 . The caregiver relationship was a significant predictor on the depression and anxiety subscales of the BSI and the organized/ structure subscale of the FES, with a trend for significance on conflict/anger and cohesion/ expression subscales. Relationship was significant on three subscales of the AAPI: lack of empathy, reversing parental roles, and belief in corporal punishment.

Post hoc comparisons on the BSI showed that biological mothers were significantly higher on depression and anxiety than all other groups of caregivers (Table 4). Their scores on both dimensions were more than twice those of other groups of caregivers. When these scores were translated into $T$ scores using Adult Nonpatient norms (Derogatis, 1993), the mean depression score had a $T$ value of 61 and the anxiety mean score a $T$ value of 59. ( $T$ scores are standardized scores with a mean of 50 and standard deviation of 10.) Both were only slightly under the value that would indicate a positive case. When we translate scores into those who score at or above the 98th percentile, there is a significant difference by 
relationship on both depression $\left(X^{2}=31.54, p=.000\right)$ and anxiety $\left(X^{2}=21.8, p=.000\right)$. On depression, $55 \%$ of the biological mothers met this level, whereas only $14 \%$ of the foster mothers, $17 \%$ of the relatives, and $26 \%$ of the comparison mothers were at this level. On anxiety, $49 \%$ of the biological mothers were at or above the 98 th percentile, whereas $16 \%$ of the foster mothers, $23 \%$ of the relatives, and $21 \%$ of the comparison mothers were at this level.

Post hoc comparisons for the organized/structure dimension of the FES found that foster mothers were higher on this dimension than comparison mothers and biological mothers, and comparison mothers were significantly lower than other types of caregivers. Post hoc comparisons on the AAPI (Table 4) showed that comparison mothers were significantly higher on the lack of empathy subscale (more empathy) than foster mothers and biological mothers. When comparing our mothers to the normative data for the general adult population, the means for all groups of mothers are below the average. The biological and relative mothers score in Bavolek's Sten 3 group and the comparison mothers in Sten 4. (Sten scores are standardized scores with a mean of 5.5 and a standard deviation of 2.) Both these are considered low but not indicative of problematic parenting. The foster mothers score in Sten group 2, which is considered problematic (Bavolek, 1984). On the reversing parental roles subscale, comparison mothers were higher than foster mothers or female relatives, but not different from biological mothers. All scores are in Stens 3 and 4, which are not considered problematic. On the belief in corporal punishment subscale, foster mothers were significantly higher on this scale (less likely to believe in corporal punishment) than comparison mothers and female relatives. They are not different from biological mothers, who are higher than female relatives and comparison mothers. Scores in this sample are below means for the norming group. Foster mothers are in Sten group 3, low but not indicative of problematic parenting. The other groups are in Sten group 2, which is indicative of problematic parenting (Bavolek, 1984).

\section{Discussion}

These results show that there are some important differences in the caregivers of children in this sample not explained by race/ethnicity, education, language, and age. These differences can be potentially quite important in creating a healing environment for children who have experienced maltreatment.

In relation to demographics, we found that foster mothers and comparison mothers had higher levels of education and income than biological mothers and kin mothers. Although it is not surprising that biological relatives would be similar to the maltreating mothers in education and income, it is interesting to note that they come from the same neighborhoods as the comparison mothers. As education and income correlate (Ashenfelter \& Rouse, 1999), this may indicate that families in which maltreatment occurs are more stressed by economic struggles than their neighbors who do not maltreat. This supports those studies that find maltreating parents are more likely to be poor (Connell, Bergeron, Katz, Saunders, \& Tebes, 2007; Drake \& Zuravin, 1998). Our foster mothers and kin caregivers were not different by age or race/ethnicity, which runs counter to other studies, which have found that kin caregivers are more likely to be older and African American (Berrick et al., 1994; Ehrle \& 
Geen, 2002). That they are less likely to be African American in our sample is not surprising because our sample is overwhelmingly minority with large numbers of Latino clients, not usual in many previous samples. Why they are similar in age is less clear, may be unique to this sample, and warrants further study.

Perhaps the most notable findings are those that relate to the ways in which biological mothers differ from the other caregivers. The biological mothers had levels of anxiety and depression that are more than twice as high as any other group of caregivers in this study. The mean levels on each measure nearly reached clinical levels, indicating that these mothers are more likely to struggle with problems of depression and anxiety. Approximately half of these mothers scored at or above the 98th percentile for both anxiety and depression, also indicating an area of concern that would likely warrant mental health treatment. These findings support those studies that have found that maltreating mothers have higher levels of depression than other groups (e.g., Famularo et al., 1994; Kelleher et al., 1994; Mammen et al., 2002; Walsh et al., 2002) and support the limited number of findings that have noted elevated rates of anxiety in maltreating mothers. It should be noted that there is a high correlation between the measures for anxiety and depression in our study. This may relate to the high rates of comorbidity between anxiety and depression found in the general population (Kessler et al., 1996), or it may be that we are tapping into a general state of dysphoria.

It is important to note that these maltreating mothers retain custody of their children and are parenting with these higher levels of problems. Given their lower levels of education and higher levels of depression and anxiety, it is likely that they are under considerable stress and may well be at risk of returning to the maltreating behaviors that brought them to the attention of child welfare authorities. On a more positive note, these mothers are less likely to endorse the use of corporal punishment than comparison mothers or kin caregivers and on that dimension are more like foster mothers, who are the least likely to approve of corporal punishment. These mothers, however, still score in an area indicating problematic parenting in relation to corporal punishment. Perhaps biological parents have benefited from their experience with the child welfare system and have become less likely to use corporal punishment. It is also possible that their psychological problems and environmental stress led to behaviors that they themselves do not approve of and could exacerbate their levels of stress. These psychological problems also may interfere with the mothers using the kinds of discipline that they feel is more appropriate. Also, possible is that they have learned through their child welfare involvement that using corporal punishment is not condoned, and therefore, they are less likely to endorse corporal punishment on measures while still resorting to using it with their children.

Both kin caregivers and comparison mothers have more favorable views of corporal punishment than foster or biological mothers. This may relate to predominant belief systems in their communities. Many of these kin caregivers have been approved as foster homes for their relatives through the child welfare system, meaning that they would have been educated on policies against corporal punishment for children in their care. It is likely that more attention is needed in helping fostering kin learn other discipline techniques that do not rely on physical punishment. It should be noted that all the mothers in this study have 
attitudes more favorable to corporal punishment than many parents, and this is likely to reflect our sample that is lower income than national averages (Bornstein, Hahn, Suwalsky, \& Haynes, 2003).

The findings on foster mothers seem somewhat inconsistent. They are higher on organized/ structure than other caregivers and less likely to view corporal punishment favorably. These family dimensions should be helpful in creating a supportive atmosphere for children in foster care. It is encouraging that foster parents are less likely to endorse using corporal punishment, and this may well relate to the foster parent training they receive that forbids corporal punishment and suggests more effective discipline techniques. The lower empathy scores are worrisome. This needs further exploration as empathy to the plight of maltreated children seems to be an important characteristic of an effective foster parent.

Kin caregivers as a group are older than the biological mothers and comparison mothers, which is to be expected, because many of these women are grandmothers to the children in their care. Their level of education is similar to the maltreating mothers, which makes it more likely that they are under some financial stress. They are more likely to view corporal punishment more favorably than foster mothers or the maltreating mothers. This indicates that the training kin caregivers receive does not seem to be effective in changing their views of this means of discipline. On a more positive note, the relative foster mothers have higher scores on the empathy measure than nonrelative foster mothers. This indicates a more positive parenting characteristic that can help them with caring for their maltreated relatives.

\section{Strengths and Limitations}

This study has a number of strengths. The first of these is that the sample is a multiethnic sample that includes a sizable number of Latino caregivers, rare in other studies on foster and maltreating parents. The sample size had sufficient numbers to allow comparisons of nonrelative and kin foster parents, especially important given the reliance on relative caregivers in current child welfare policy. Additionally, this study had a comparison group, which many studies do not, who came from the same neighborhoods as the maltreating parents, allowing a better comparison among the different caregivers.

There are a number of limitations that need to be noted. The sample was not random, limiting its generalizability. We measured only the caregiver's attitudes toward parenting and the family situation, which may not be an accurate representation of their actual parenting or family environment. Responses to questions could well be influenced by social desirability, particularly on the questions related to corporal punishment. In addition, we did not have information about the services families were receiving or had received before the interviews, and these services could have influenced their responses.

\section{Implications}

A number of practice and policy implications follow from this study. The most important of these relates to the difficulties of the maltreating mothers who retain custody of their children. It is their higher rates of depression and anxiety that are more notably different than their parenting attitudes. These dynamics are likely to interfere with their parenting. Interventions that only aim to improve their parenting skills may miss the most important 
dynamics that affect their problematic parenting. Assessment of psychological functioning and intervention, when appropriate, may be the most essential component of improving their parenting. Attending to the needs of the mothers is vital to improve the outcome of the children in their care. We have previously found that the maltreated children who remain at home have the same rates of mental health problems as those in care and many meet clinical symptom levels (Mennen, Brensilver, \& Trickett, 2010; Mennen \& Trickett, 2007). Given the mutual interactive effect of parent and child mental health problems (Elgar, McGrath, Waschbusch, Stewart, \& Curtis, 2004), it is unlikely that children's conditions will improve without parent treatment.

Getting the appropriate treatment for mothers is hampered by both child welfare policies and mental health funding. Currently, if a family receives interventions from child welfare, they are likely to focus on improving parenting skills and environmental conditions that relate to the maltreatment. Some families receive no services if the department feels that the child is not at serious risk. Mental health interventions are less likely to occur and are beyond the scope of child welfare to deliver. Workers may refer parents to mental health agencies, but declining state budgets have meant cuts in mental health care, making appropriate treatment for these mothers even more problematic. Child welfare agencies should find ways to ensure that maltreating mothers who retain custody of their children are provided comprehensive services that address the full range of problems, including their psychological functioning.

When children are placed, their caregivers, both kin and nonkin, have needs that should be addressed. Foster parents would appear to benefit from interventions to help them gain more empathy toward the children in their care. Perhaps some of the effective models of increasing empathy in health care providers (Bonvicini, Perline, Bylulnd, Rouse, \& Goldstein, 2009; Gülsüm, 2006) and Webster-Stratton's (Webster-Stratton \& Reid, 2010) focus on empathy building in the Incredible Years program can be adapted for foster parents and included as part of their training. Kin caregivers may benefit from more training and support related to discipline so that they have alternate strategies to corporal punishment.

Additionally, more research is needed to better understand how these attributes of parents affect children's functioning. Such understanding can guide decisions on follow-up services for the caregivers to ensure that the placement of the maltreated child is a success.

\section{Acknowledgments}

This study was funded by Grant \#5 R01 HD 39129-02 from the National Institute of Child Health and Human Development.

\section{References}

Allen M, Bissell M. Safety and stability for foster children: The policy context. The Future of Children. 2004; 14:49-73.

Ashenfelter, OC., Rouse, CE. Schooling, intelligence, and income in America: Cracks in the bell curve. SSRN; 1999. NBER Working Paper No. W6902Retrieved September 20, 2008, from http:// ssrn.com/abstract $=147430$

Barth RP, Green R, Webb MB, Wall A, Gibbons C, Craig C. Characteristics of out-of-home caregiving environments provided under child welfare services. Child Welfare. 2008; 87:5-39. 
Baumann BL, Kolko DJ. A comparison of abusive and nonabusive mothers of abused children. Child Maltreatment. 7:369-376. [PubMed: 12408248]

Bavolek, SJ. Handbook for the Adult-Adolescent Parenting Inventory. Park City, UT: Family Development Resources, Inc; 1984.

Bavolek, SJ., Keene, RG. Adult-Adolescent Parenting Inventor-AAPI-2: Administration and development handbook. Park City, UT: Family Development Resources, Inc; 1999.

Belsky J. Etiology of child maltreatment: A developmental-ecological analysis. Psychological Bulletin. 1993; 114:413-134. [PubMed: 8272464]

Berrick J, Barth R, Needell B. A comparison of kinship foster homes and foster family homes: Implications for kinship foster care as family preservation. Children and Youth Services Review. 1994; 16:22-63.

Berrick JD. Assessing quality of care in kinship and foster family care. Family Relations. 1997; 46:273-280.

Bonvicini KA, Perline MJ, Bylulnd GC, Rouse RA, Goldstein MG. Impact of communication training on physician expression of empathy in patient encounters. Patient Education and Counseling. 2009; 75:3-10. [PubMed: 19081704]

Bornstein, MH., Hahn, C., Suwalsky, J., Haynes, OM. Socioeconomic status, parenting, and child development: The Hollingshead Four-Factor Index of Social Status and the Socioeconomic Index of Occupations. In: Bornstein, MH., Bradley, R., editors. Socioeconomic status, parenting, and child development. Mahwah, NJ: Lawrence Erlbaum; 2003. p. 29-82.

Boyd CP, Gullone E, Neddleman GL, Burt T. The Family Environment Scale: Reliability and normative data for an adolescent sample. Family Process. 1997; 36:369-373. [PubMed: 9543658]

Bronfenbrenner, U. The ecology of human development: Experiments by nature and design. Cambridge, MA: Harvard University Press; 1979.

Brooks D, Barth R. Characteristics and outcomes of drug-exposed and non-drug-exposed children in kinship and non-relative foster care. Children and Youth Services Review. 1998; 20:475-501.

Brunnquell D, Crichton L, Egeland B. Maternal personality and attitude in disturbances of child rearing. American Journal of Orthopsychiatry. 1981; 51:680-691. [PubMed: 7294172]

Burke L. The impact of maternal depression on familial relationships. International Review of Psychiatry. 2003; 15:243-255. [PubMed: 15276963]

Christenson D, McMurtry J. A comparative evaluation of preservice training of kinship and nonkinship foster/adoptive families. Child Welfare Journal. Special Issue: Adoption. 2007; 86:125-140.

Cicchetti D, Toth SL. A developmental psychopathology perspective on child abuse and neglect. Journal of the American Academy of Child and Adolescent Psychiatry. 1995; 34:541-565. [PubMed: 7775351]

Clay CM, Ellis MA, Griffin ML, Amodeo M, Fassler IR. Black women and white women: Do perceptions of childhood family environment differ? Family Process. 2007; 46:243-256. [PubMed: 17593888]

Cole SA, Eamon MK. Predictors of depressive symptoms among foster caregivers. Child Abuse \& Neglect. 2007; 31:295-310. [PubMed: 17442391]

Connell CM, Bergeron N, Katz KH, Saunders L, Tebes JK. Rereferral to child protective services: The influence of child, family, and case characteristics on risk status. Child Abuse \& Neglect. 2007; 31:573-588. [PubMed: 17537504]

Conners NA, Whiteside-Mansell L, Deere D, Ledet T, Edwards MC. Measuring the potential for child maltreatment: The reliability and validity of the Adult Adolescent Parenting Inventory-2. Child Abuse \& Neglect. 2006; 30:39-53. [PubMed: 16406026]

Cummings PT, Davies PT. Maternal depression and child development. Journal of Child Psychology and Psychiatry. 1994; 35:73-112. [PubMed: 8163630]

De Robertis MT, Litrownik AJ. The experience of foster care: Relationship between foster parent disciplinary approaches and aggression in a sample of young foster children. Child Maltreatment. 2004; 9:92-102. [PubMed: 14871000]

Derogatis, LR. SCL-90-R; Administration, scoring and procedures: Manual II. Towson, MD: Clinical Psychometric Research; 1993. 
Derogatis LR, Melisaratos N. The Brief Symptom Inventory: An introductory report. Psychological Medicine. 1983; 13:595-605. [PubMed: 6622612]

Devoe ER, Kantor GK. Measurement issue in child maltreatment and family violence prevention programs. Trauma, Violence, \& Abuse. 2002; 3:15-39.

Drake B, Zuravin S. Bias in child maltreatment reporting: Revisiting the myth of classlessness. American Journal of Orthopsychiatry. 1998; 68:295-304. [PubMed: 9589767]

Duncan, GJ., Aber, JL. Neighborhood models and measures. In: Brooks-Gunn, J.Duncan, GJ., Aber, JL., editors. Neighborhood poverty: Context and consequences for children. Vol. 1. New York: Russell Sage Foundation; 1997. p. 62-78.

Ehrle J, Geen R. Kin and non-kin foster care-Findings from a national survey. Child Welfare. 2002; 24:15-35.

Elgar FJ, McGrath PJ, Waschbusch DA, Stewart SH, Curtis LJ. Mutual influences on maternal depression and child adjustment problems. Clinical Psychology Review. 2004; 24:441-459. [PubMed: 15245830]

Famularo R, Fenton T, Kinscherff R, Ayoub C, Barnum R. Maternal and child posttraumatic stress disorder in cases of child maltreatment. Child Abuse \& Neglect. 1994; 18:27-36. [PubMed: 8124596]

Gaudin JM, Sutphen R. Foster care vs. extended family care for children of incarcerated mothers. Journal of Offender Rehabilitation. 1993; 19:129-147.

Gebel TJ. Kinship care and non-relative family foster care: A comparison of caregiver attributes and attitudes. Child Welfare. 1996; 75:5-18.

Gibbs D, Wildfire J. Length of service for foster parents: Using administrative data to understand retention. Children and Youth Services Review. 2007; 29:588-599.

Goodman E. The role of socioeconomic status gradients in explaining differences in US adolescents' health. American Journal of Public Health. 1999; 89:1522-1528. [PubMed: 10511834]

Goodman E, Huang B. Socioeconomic status, depressive symptoms, and adolescent substance use. Archives of Pediatric and Adolescent Medicine. 2002; 156:448-453.

Gülsüm A. Developing empathy in nurses: An inservice training program. Archives of Psychiatric Nursing. 2006; 20:249-257. [PubMed: 17145452]

Harden BJ, Clyman RB, Kriebel DK, Lyone ME. Kith and kin care: Parental attitudes and resources of foster and relative caregivers. Children and Youth Services Review. 2004; 26:657-671.

Haskett ME, Scott SS, Grant R, Ward CS, Robinson C. Child-related cognitions and affective functioning of physically abusive and comparison parents. Child Abuse \& Neglect. 2003; 27:663686. [PubMed: 12818613]

Holton A, Ronning JA, Handegard BH, Sourander A. A comparison of mental health problems in kinship and nonkinship foster care. European Child and Adolescent Psychiatry. 2005; 14:200-207. [PubMed: 15981131]

Iwamasa GY, Kooreman H. Brief Symptom Inventory scores of Asian, Asian-American, and European-American college students. Cultural Diversity \& Mental Health. 1995; 1:149-157. [PubMed: 9225555]

Kaufman J, Charney D. Comorbidity of mood and anxiety disorders. Depression and Anxiety. 2000; 12(S1):S69-S76.

Kelleher K, Chaffin M, Hollenberg J, Fisher E. Alcohol and drug disorders among physically abusive and neglectful parents in a community-based sample. American Journal of Public Health. 1994; 84:1586-1590. [PubMed: 7943475]

Keller TE, Wetherbee K, LeProhn NS, Payne V, Sime K, Lamont ER. Competencies and problem behaviors of children in family foster care: Variations by kinship placement status and race. Children and Youth Services Review. 2001; 23:915-940.

Kessler RC, Nelson CB, McGonagle KA, Edlund MJ, Frank RG, Leaf PJ. The epidemiology of cooccurring addictive and mental disorders: Implications for prevention and service utilization. American Journal of Orthopsychiatry. 1966; 66:17-31.

Kinard EM. Social support, competence, and depression in mothers of abused children. American Journal of Orthopsychiatry. 1996; 66:449-462. [PubMed: 8827268] 
Krueger RF. The structure of common mental disorders. Archives of General Psychiatry. 1999; 56:921-926. [PubMed: 10530634]

Linares LO, Montalto D, Rosbruch N, Li M. Discipline practices among biological and foster parents. Child Maltreatment. 2006; 11:157-167. [PubMed: 16595849]

Lipton M. The effect of the primary caretaker's distress on the sexually abused child: A comparison of biological and foster parents. Child and Adolescent Social Work. 1997; 14:162-174.

Litrownik AJ, Newton R, Mitchell BE, Richardson KK. Long term follow-up of young children placed in foster care. Journal of Family Violence. 2003; 18:19-28.

Lovejoy MD, Graczyk PA, O’Hare E, Neuman G. Maternal depression and parenting behavior: A meta-analytic review. Clinical Psychology Review. 2000; 20:561-592. [PubMed: 10860167]

Mammen OK, Kolko DJ, Pilkonis PA. Negative affect and parental aggression in child physical abuse. Child Abuse \& Neglect. 2002; 26:407-424. [PubMed: 12092806]

Mennen FE, Brensilver M, Trickett P. Do maltreated children who remain at home function better than those who are placed? Children and Youths Services Review. 2010; 32:1675-1682.

Mennen FE, Kim K, Sang J, Trickett PK. Child neglect: Definition and identification of adolescents' experiences. Child Abuse \& Neglect. 2010; 34:647-658. [PubMed: 20643482]

Mennen FE, Trickett P. Mental health services to urban minority children. Children and Youth Services Review. 2007; 29:1220-1234.

Milner JS, Gold RG, Wimberley RC. Prediction and explanation of child abuse: Cross-validation of the Child Abuse Potential Inventory. Journal of Consulting and Clinical Psychology. 1986; 54:865866. [PubMed: 3794036]

Mollerstrom WW, Patchner MA, Milner JS. Family functioning and child abuse potential. Journal of Clinical Psychology. 1992; 48:445-454. [PubMed: 1517438]

Moos, RH., Moos, BS. Family Environment Scale manual. Palo Alto, CA: Consulting Psychologists Press; 1994.

Negy C, Snyder DK. Assessing family-of-origin functioning in Mexican American adults. Assessment. 2006; 13:396-405. [PubMed: 17050910]

Orme JG, Buehler C. Foster family characteristics and behavioral problems of foster children: A narrative review. Family Relations. 2001; 50:3-15.

Orme JG, Buehler C, McSurdy M, Rhodes KW, Cox ME, Patterson DA. Parental and familial characteristics of family foster care applicants. Children and Youth Services Review. 2004; 26:307-329.

Perry MA, Wells EA, Doran LD. Parent characteristics in abusing and nonabusing families. Journal of Clinical Child Psychology. 1983; 12:329-336.

Ruiperez MA, Ibanez MI, Lorente E, Moro M, Ortet G. Psychometric properties of the Spanish version of the BSI: Contributions to the relationship between personality and psychopathology. European Journal of Psychological Assessment. 2001; 17:241-250.

Sanford K, Bingham CR, Zucker RA. Validity issues with the Family Environment Scale: Psychometric resolution and research application with alcoholic families. Psychological Assessment. 1999; 11:315-325.

Timmer SG, Sedlar G, Urquiza A. Challenging children in kin versus nonkin foster care: Perceived costs and benefits to caregivers. Child Maltreatment. 2004; 9:251-262. [PubMed: 15245678]

Trickett PK, Susman EJ. Parental perceptions of child-rearing practices in physically abusive and nonabusive families. Developmental Psychology. 1988; 24:270-276.

Trickett PT, Mennen FE, Kim K, Sang J. Emotional abuse in a sample of multiply-maltreated, urban young adolescents: Issues of definition and identification. Child Abuse \& Neglect. 2009; 33:2735. [PubMed: 19178945]

U.S. Department of Health and Human Services, Administration for Children and Families, Administration on Children, Youth and Families, Children's Bureau. The AFCARS Report \#16: Preliminary FY 2008 Estimates as of October, 2009. 2009a. Retrieved January 26, 2010, from http://www.acf.hhs.gov/programs/cb/stats_research/afcars/tar/report16.htm 
U.S. Department of Health and Human Services, Administration on Children Youth and Families. Child maltreatment 2007. Washington, DC: U.S. Government Printing Office; 2009b. Retrieved January 26, 2010, from http://www.acf.hhs.gov/programs/cb/stats_research/index.htm\#can

Walsh C, MacMillan H, Jamieson E. The relationship between parental psychiatric disorder and child physical abuse and sexual abuse: Findings from the Ontario Health Supplement. Child Abuse \& Neglect. 2002; 26:11-22. [PubMed: 11860159]

Webster-Stratton, C., Reid, J. The Incredible Years parent, teachers, and children training series: A multifaceted treatment approach for young children with conduct problems. In: Weisz, JR., Kazdin, AE., editors. Evidence-based psychotherapies for children and adolescents. 2. New York: Guilford Press; 2010. p. 194-210.

Whipple EE, Webster-Stratton C. The role of parental stress in physically abusive families. Child Abuse \& Neglect. 1991; 15:279-291. [PubMed: 2043979]

Wiehe VR. Empathy and narcissism in a sample of child abuse perpetrators and a comparison sample of foster parents. Child Abuse \& Neglect. 2003; 27:541-555. [PubMed: 12718962]

Zuravin SJ. Severity of maternal depression and three types of mother-to-child aggression. American Journal of Orthopsychiatry. 1989; 59:377-389. [PubMed: 2764072] 

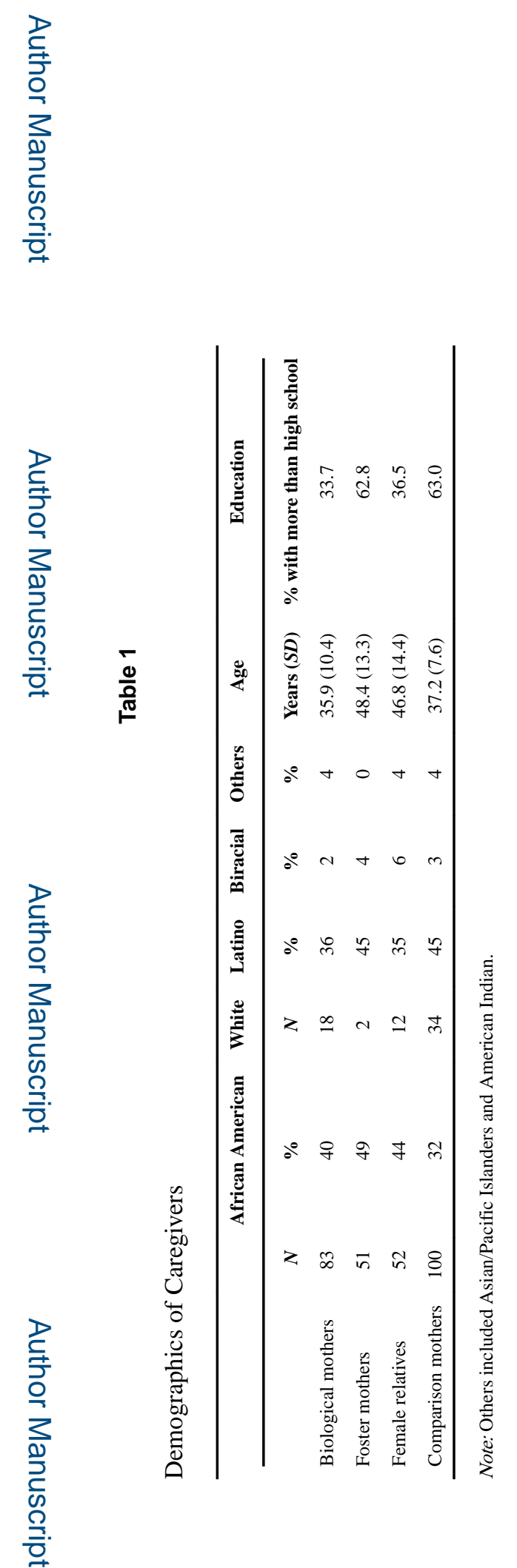

Fam Relat. Author manuscript; available in PMC 2017 December 07. 


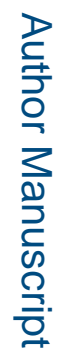

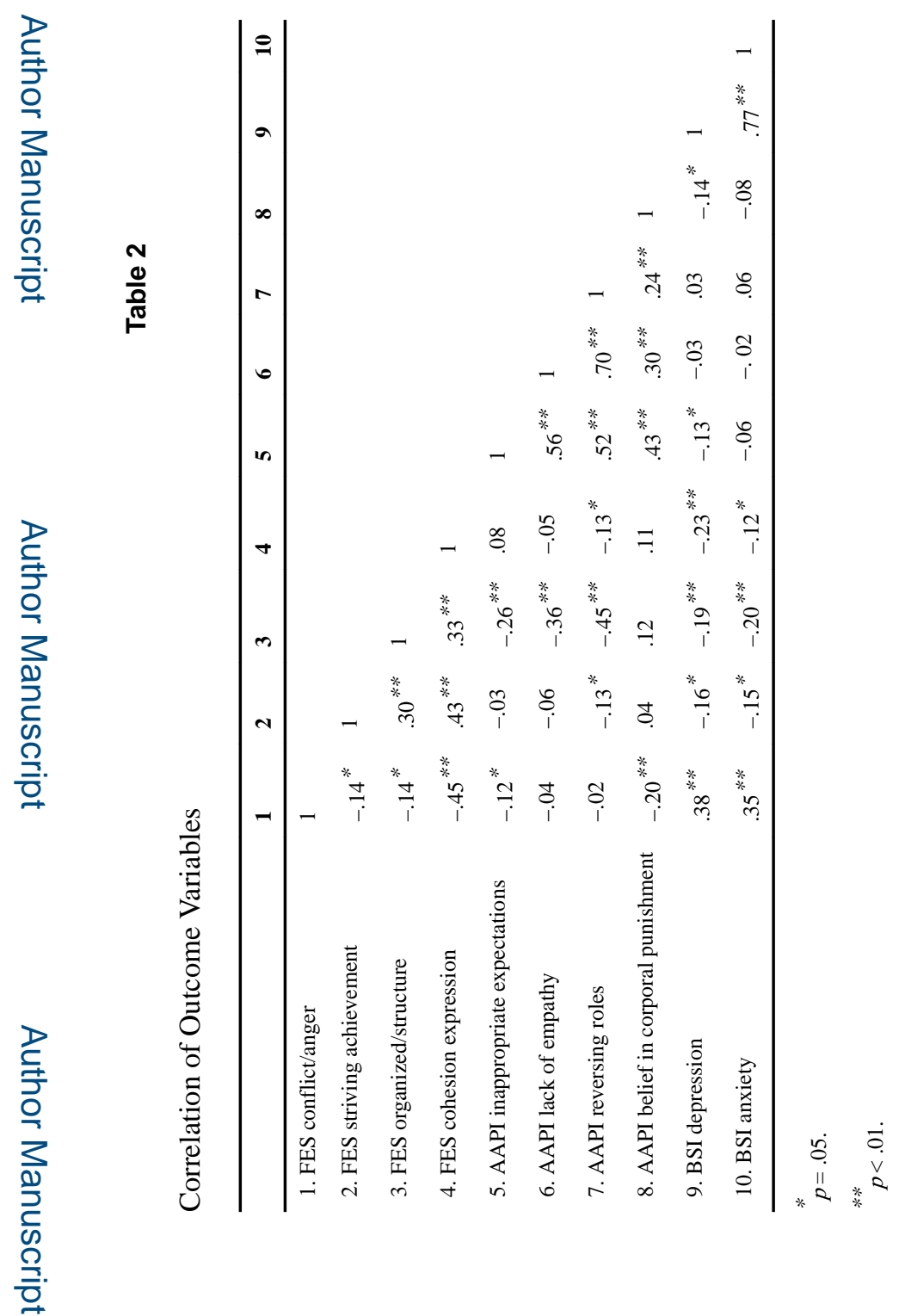

Fam Relat. Author manuscript; available in PMC 2017 December 07. 


\section{Table 3}

MANCOVA Results for Caregiver Relationship

\begin{tabular}{lcc}
\hline Dependent Variable & $\boldsymbol{F}$ & Significance \\
\hline BSI & & \\
$\quad$ Depression & 4.49 & .004 \\
$\quad$ Anxiety & 3.59 & .014 \\
FES & & \\
$\quad$ Conflict anger & 2.15 & .095 \\
Organized/structure & 6.71 & .000 \\
Cohesion/expression & 2.23 & .097 \\
AAPI & & \\
Inappropriate expectations & 1.15 & .328 \\
Lack of empathy & 3.51 & .016 \\
Reversing parental roles & 3.05 & .029 \\
Belief in corporal punishment & 4.06 & .008 \\
\hline
\end{tabular}

Note: Control variables in equation ethnicity, education, age, and language. 


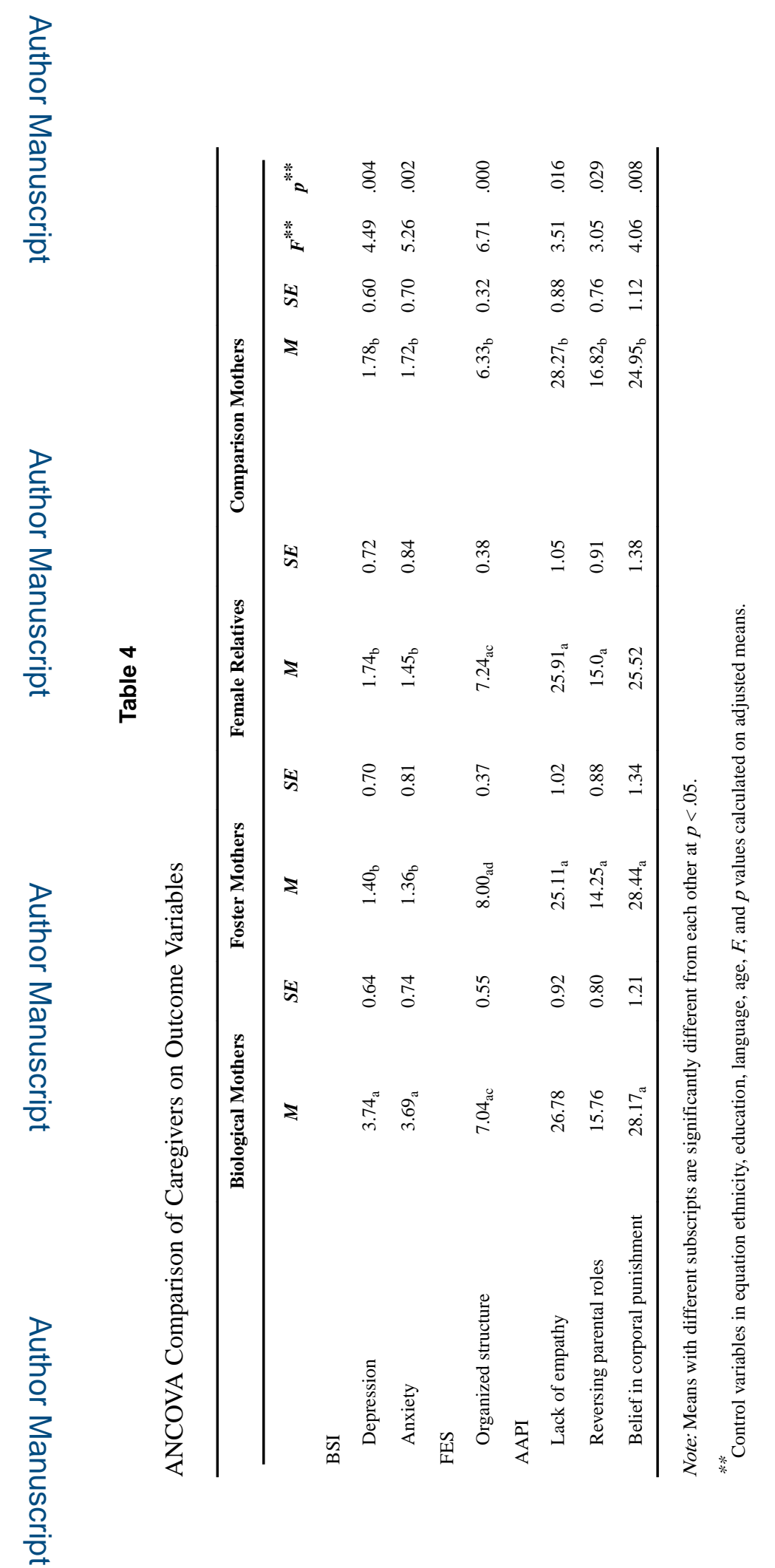

Fam Relat. Author manuscript; available in PMC 2017 December 07. 